\title{
PENERAPAN DISK MILL PADA UMKM ANUGERAH PRODUKSI VITAMIN UNGGAS DI DESA SEKARMOJO KECAMATAN PURWOSARI
}

\author{
Djoko Hari Praswanto ${ }^{1 *}$, Soeparno Djiwo ${ }^{2}$, Mochtar Asroni ${ }^{3}$, Lalu Mustiadi ${ }^{4}$, \\ Thomas Priyasmanu ${ }^{5}$ \\ 1,2,3,4 Jurusan Teknik Mesin S-1, Fakultas Teknologi Industri, Institut Teknologi Nasional Malang \\ ${ }^{5}$ Jurusan Teknik Industri S-1, Fakultas Teknologi Industri, Institut Teknologi Nasional Malang \\ *Email Korespondensi: djoko@lecturer.itn.ac.id
}

Submitted : 1 Desember 2020; Revision : 15 Desember 2021; Accepted : 15 Februari 2021

\begin{abstract}
ABSTRAK
Vitamin unggas merupakan salah satu nutrisi yang dibutuhkan oleh peternak. Vitamin unggas ini berfungsi untuk mempercepat pertumbuhan, menjaga kualitas daging, memperbaiki kualitas telur, memperpanjang produksi telur dan mempercepat produksi telur unggas. Salah satu mitra yang menjadi rekan kerja sama tim pengabdian ITN Malang yaitu bergerak dibidang pembuatan vitamin unggas dan ingin meningkatkan omset pembuatan vitamin unggas. Selama ini vitamin unggas dari pabrik dirasa harganya cukup tinggi sehingga peternak merasa keberatan untuk membeli vitamin unggas dari pabrik. Tim pengabdian mengamati kualitas produksi dan mentransfer teknologi dengan menerapkan disk mill pada proses produksi yang mampu meningkatkan produksi vitamin unggas dengan harga yang terjangkau dan berkualitas. Selain itu tim akan memperbaiki pengemasan yang menggunakan aluminiun foil untuk menghindari kelembaban dan diberi logo untuk memudahkan penjualan ke peternak. Diharapkan setelah memperbaiki pengemasan, vitamin unggas ini dapat di pasarkan secara bebas dengan memenuhi standarisasi vitamin unggas pada umumnya. Sehingga peternak dapat mendapatkan vitamin unggas yang murah dan berkualitas. Dari hasil kegiatan yang telah dilakukan didapatkan mesin disk mill dengan kapasitas $150 \mathrm{~kg} / \mathrm{jam}$. Jika produksi yang dihasilkan $500 \mathrm{~kg}$ membutuhkan waktu 3 jam dengan jumlah pekerja 1 orang. Sehingga mitra dapat menghemat waktu dan biaya produksi. Keuntungan yang didapatkan oleh mitra sekarang meningkat $25 \%$ dari keuntungan sebelumnya. Sedangkan sekarang kemasan yang digunakan oleh mitra adalah alumunium foil dengan tampilan produk yang lebih menarik dan tetap kering.
\end{abstract}

Kata kunci : Vitamin unggas, Disk Mill, Kemasan, Alumunium Foil

\begin{abstract}
Poultry vitamins are one of the nutrients needed by breeders. This poultry vitamin serves to accelerate growth, maintain meat quality, improve egg quality, prolong egg production and accelerate the production of poultry eggs. One of the partners working together with the ITN Malang service team is engaged in the manufacture of poultry vitamins and wants to increase the poultry vitamins' turnover. So far, the price of poultry vitamins from factories is considered high enough so that farmers have objections to buying poultry vitamins from factories. The community service team observes the quality of production and transfers technology by implementing a disk mill in the production process which can increase the production of poultry vitamins at affordable prices and quality. Also, the team will improve packaging that uses aluminium foil to avoid moisture and will be given a logo to facilitate sales to breeders. It is hoped that after improving the packaging, this poultry vitamin can be marketed freely by meeting the standardisation of poultry vitamins in general. So that breeders can get cheap and quality poultry vitamins. From the results of the activities carried out, it was found that a disk mill machine with a capacity of $150 \mathrm{~kg} / \mathrm{hour}$. If the products produced is $500 \mathrm{~kg}$, it takes 3 hours with 1 worker. So that partners can save time and production costs. The profit earned by the partner is now an increase of $25 \%$ from the previous profit. Meanwhile, the packaging used by partners is aluminium foil with a more attractive product appearance and remains dry.
\end{abstract}

Keywords : Poultry vitamins, Disk Mill, Packaging, Aluminum Foil. 


\section{PENDAHULUAN}

Salah satu potensi usaha untuk dikembangkan lebih maju lagi di Desa Sekarmojo Kecamatan Purwosari Kabupaten Pasuruan sesuai dengan kebutuhan masyarakat yang rata - rata sebagai peternak unggas adalah produksi vitamin unggas. Di daerah Sekarmojo kecamatan Purwosari, peternak unggas cukup banyak, sehingga pengembangan produksi vitamin unggas cukup berpotensi meningkatkan usaha mikro khususnya mitra produksi vitamin unggas dan umumnya peternak di Daerah Purwosari. Seperti pada UMKM Anugerah selaku mitra pengabdian masyarakat ini telah memproduksi vitamin unggas mulai tahun 2011. Selama awal usaha sampai sekarang ini dalam pembuatan vitamin tersebut masih manual dengan menggunakan tenaga manusia tanpa sentuhan teknologi. Dari hasil produksi secara manual ini cukup memakan waktu yang lama, kualitas campuran tidak merata dan membutuhkan tenaga kerja yang banyak. Sehingga beberapa poin permasalahan tersebut dapat merusak kualitas produksi. Salah satu penyebab lambatnya perkembangan mitra ini yaitu permasalahan dalam produksi yang dilakukan secara manual. Sehingga permintaan konsumen tidak mengalami peningkatan. Beberapa tahun ini, pemilik mitra berusaha memperbaiki kualitas produksinya dengan cara memberikan alas terpal sebagai alas campuran. Hal ini dilakukan untuk mempermudah pencampuran merata. Tetapi model penyelesaian masalah seperti ini belum bisa menyelesaikan seratus persen. Ada juga timbul masalah proses produksi lainnya yaitu, proses penghancuran bahan baku dari bentuk granul dijadikan menjadi tepung.

Dari hasil kunjungan tim pengabdian menganalisa bahwa usaha ini cukup berpontesi untuk dikembangkan dalam hal pembuatan vitamin unggas. Hasil survei selain dari pemilik mitra pembuat vitamin, tim pengabdian juga survei kualitas vitamin ke peternak langsung. Hasil produksi vitamin dari mitra kualitas vitamin lebih bagus dibanding dari pabrik. Hal ini sudah dilakukan uji coba oleh peternak - peternak unggas. Selain kualitas lebih bagus harga vitamin dari mitra relatif lebih murah, sehingga dapat meningkatkan keuntungan peternak. Hanya peternak memberikan masukan bahwa hasil vitamin pencampurannya kurang merata, masih ada butiran besar yang belum menjadi tepung sehingga peternak melakukan penghancuran kembali. Pada saat melakukan peninjauan ditempat mitra, selain mencari permasalahan - permasalahan mitra juga melakukan diskusi lebih lanjut dengan para peternak dan hasil diskusi para peternak, mitra dan tim pengabdian siap melakukan kerja sama dalam mengembangkan usaha ini. Dengan mempertimbangkan keadaan mitra, tim pengabdian dapat menarik kesimpulan permasalahan - permasalahan utama yaitu di produksi yang harus diselesaikan selama program PKM ini berjalan. Sedangkan mitra sendiri juga mempunyai konsep akan mengembangkan hasil produknya dengan memperbanyak macam - macam vitamin unggas dan akan bergerak ke sektor perikanan dan peternak sapi.

Vitamin unggas yang diproduksi mitra selama ini dikenal dengan nama bromix. Bromix ini merupakan vitamin unggas khusus untuk unggas petelur. Vitamin ini mempunyai keunggulan memperbaiki kualitas telur unggas, memperpanjang produksi telur unggas dan mempercepat produksi telur unggas (Mahmud, 2020). Dalam pembuatan bromix ini, pemilik mitra sudah mempunyai komposisi campuran bahan. Sebelum dilakukan pencampuran bahan, bahan - bahan tersebut ditimbang terlebih dahulu sesuai dengan formulasi yang dibuat pemilik. Setelah bahan ditimbang, dilakukan penghancuran terlebih dahulu secara manual. Setelah proses penghancuran dilakukan pencampuran. Pencampuran yang dilakukan selama ini secara manual oleh pekerja tanpa bantuan teknologi. Selama proses produksi waktu yang dibutuhkan 6 jam dengan kapasitas 500 $\mathrm{kg}$.

Setelah proses pencampuran, pengelola melakukan pengemasan produk. Sekarang ini pengemasan vitamin unggas menggunakan karung yang ditali biasa. Dengan metode pengemasan seperti banyak permasalahan yang timbul yaitu, tampilan kemasan yang kurang menarik, mudah bocor dan tidak tahan lama dalam penyimpanan. Dari hasil 
analisis situasi yang ada di mitra, ada beberapa masalah yang bisa diselesaikan yaitu mesin disk mill sebagai solusi permasalahan pada proses produksi pada saat penghancuran bahan baku menjadi tepung dan alumunium foil sebagai bahan kemasan.

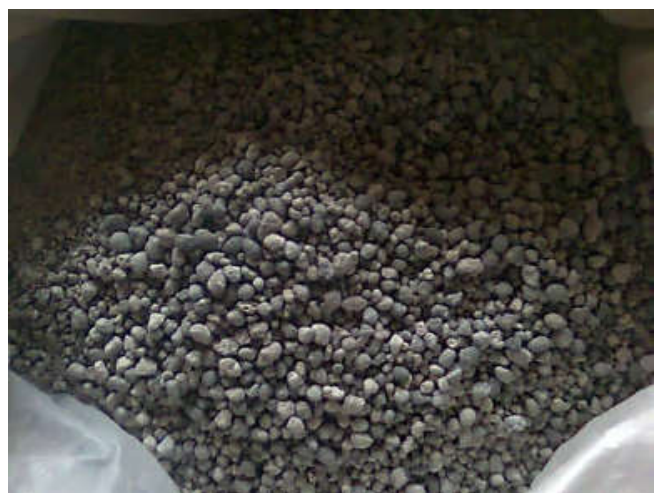

Gambar 1. Bahan Baku Vitamin Sebelum Dihancurkan
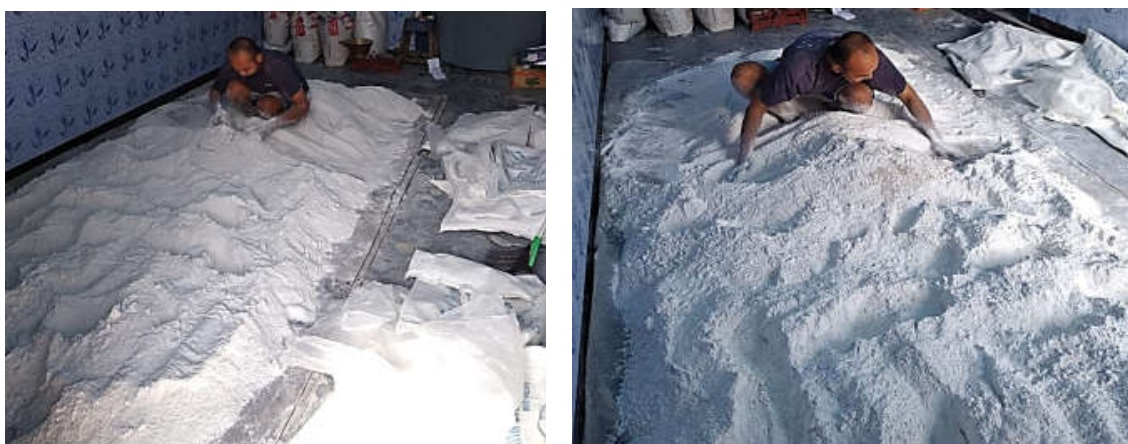

Gambar 2. Pencampuran Secara Manual

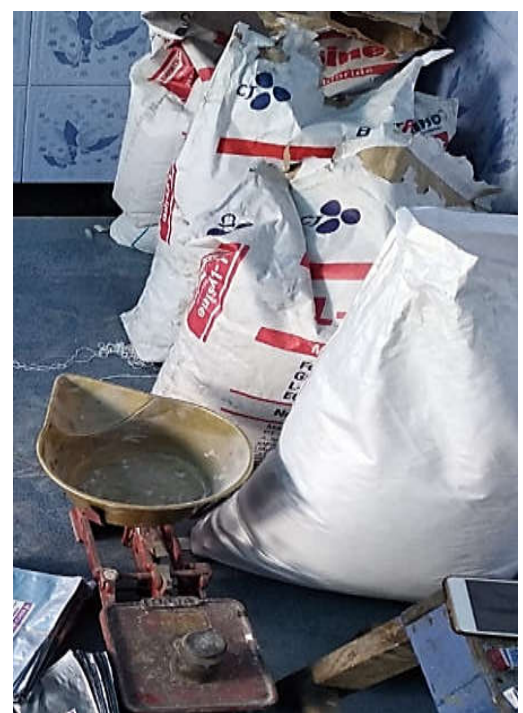

Gambar 3. Pengemasan Vitamin Unggas

\section{METODE}

Metode pendekatan yang akan dilakukan dalam memecahkan persoalan di mitra yaitu sumber daya manusia perlu diprioritaskan On The Job Training (OJT) adalah melatih 
seseorang untuk mempelajari pekerjaan sambil mengerjakannya. Karyawan memperoleh pelatihan, sehingga dapat memperoleh umpan balik secara langsung dari pelatihnya (Baccara, Lee and Yariv, 2020; Kafiabad, Kazemi Zanjani and Nourelfath, 2020). Keuntungan dari metode ini adalah relatif tidak mahal, peserta pelatihan bisa belajar sambil tetap menjalankan proses produksi dan tidak memerlukan ruangan khusus. Pada kegiatan pengabdian masyarakat ini ada beberapa langkah yang perlu dilakukan, yaitu :

\section{Pembuatan mesin Disk Mill}

Dalam menyelesaikan permasalahan dibidang produksi tim PKM ITN Malang akan merancang teknologi tepat guna (Djiwo, Pohan and Praswanto, 2019; Praswanto, Djiwo and Setyawan, 2019). Mesin disk mill vitamin unggas ini menggunakan penggerak motor listrik (Aman et al., 2017; Sukmafitri, Ragadhita and Nandiyanto, 2020). Dari rancangan mesin ini nantinya akan menghasilkan kualitas vitamin unggas yang sama rata karena dalam penghancuran menggunakan manual butiran tidak bisa lembut sehingga dalam pencampuran tidak merata. Sedangkan untuk waktu yang dibutuhkan sedikit dan satu mesin ini bisa dioperasikan satu orang pekerja.

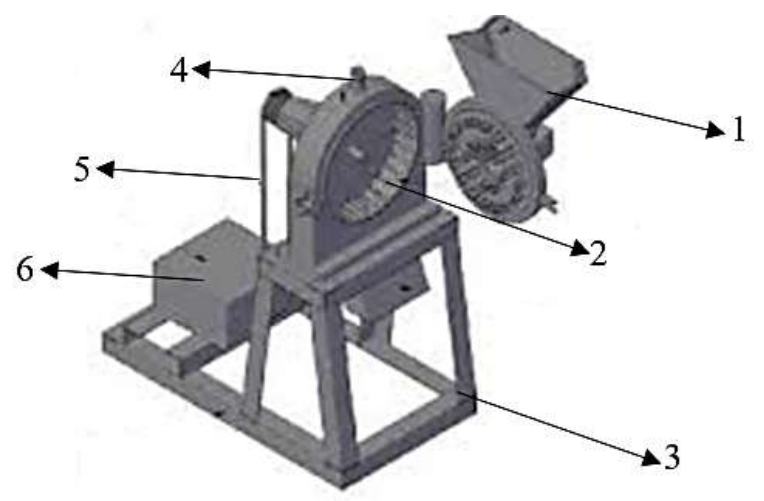

Keterangan gambar :

Gambar 4. Mesin Pengaduk Vitamin Unggas

1. Chopper

2. Gigi penghancur

3. Rangka mesin

4. Cover mesin

5. V- belt penghubung

6. Motor listrik

\section{Pembuatan Kemasan}

Selain teknologi tepat guna mesin disk mill vitamin unggas, tim PKM merencanakan solusi dalam pengemasan. Untuk mengemas produk vitamin unggas ini agar lebih menarik, akan menggunakan kemasan alumunium foil dengan ditambahkan label dibagian depan (Nurhaeda, Muhammad Siri Dangnga, 2019; Marsigit et al., 2020). Kemasan model seperti ini membutuhkan sealer untuk menutup bagian atas.

\section{Coaching dan Pendampingan}

Dimana mitra akan didampingi oleh tim pengabdian serta mahasiswa tugas akhir yang lebih berpengalaman dari segi teknologi. Hubungan kelompok adalah berupa anggota pelatihan dan tutor. Cara ini akan berjalan efektif apabila waktu pertemuan selama bimbingan/pelatihan dan umpan balik lebih panjang artinya kelompok memiliki waktu luang yang cukup untuk menyelesaikan materi pelatihan. 


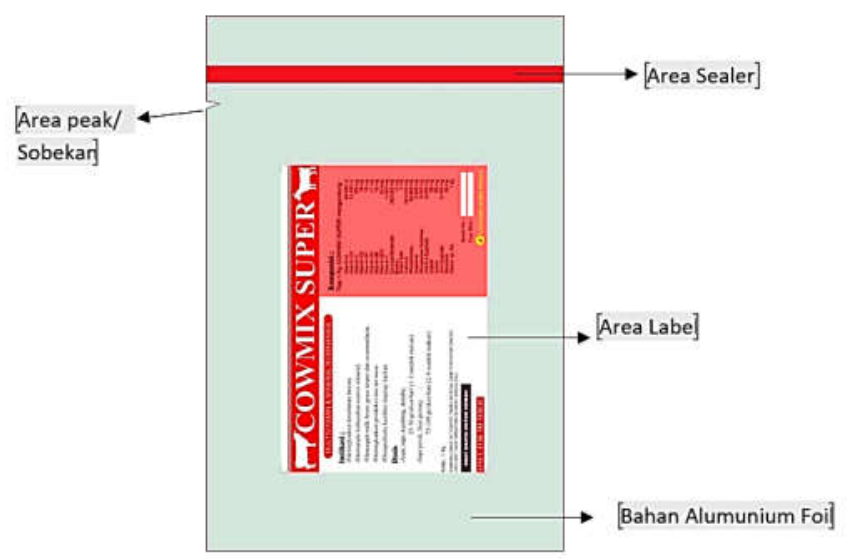

Gambar 5. Desain Kemasan

\section{HASIL DAN PEMBAHASAN}

Kegiatan pengabdian masyarakat bekerja sama dengan UMKM Anugerah yang bergerak dibidang produksi vitamin unggas ini mendapatkan hasil sesuai yang diharapkan. Dari beberapa permasalahan yang dihadapi oleh mitra dapat terselesaikan dengan baik. Secara analisis situasi pada mitra memiliki dua permasalahan yaitu pada proses produksi penghancuran bahan baku dari bentuk granul menjadi tepung dan pengemasan yang kurang menarik dan efisien. Dengan melakukan metode yang digunakan, maka hasil dari pengabdian ini berupa teknologi tepat guna mesin disk mill dan kemasan dari bahan alumunium foil.

Langkah awal yang dilakukan oleh tim pengabdian masyarakat yaitu perencanaan dan pembuatan mesin disk mill seperti yang ditunjukkan Gambar 6. Perencanaan mesin disk mill vitamin unggas ini memiliki spesifikasi yaitu :

Dimensi

: $100 \mathrm{~cm} \times 100 \mathrm{~cm} \times 90 \mathrm{~cm}$

Daya motor

$: 1,5 \mathrm{HP}$

Kecepatan motor

$: 2800 \mathrm{rpm}$

Daya listrik

: 1100 watt

Kecepatan shaft

: $5600 \mathrm{rpm}$

Ukuran saringan

: 80 mesh, 90 mesh, 100 mesh

Kapasitas mesin

$$
: 150 \mathrm{~kg} / \mathrm{jam}
$$

Setelah proses pembuatan mesin disk mill vitamin unggas dilakukan uji coba mesin menggunakan bahan baku vitamin unggas yang didapat di mitra. Pada kegiatan uji coba ini dilakukan di tempat mitra karena sekaligus kegiatan pelatihan. Hal ini dilakukan agar mitra juga mengetahui proses penggunaan mesin dan perawatannya. Uji coba dilakukan 3 kali untuk dapat melihat kinerja mesin yang optimal. Dari hasil uji coba didapatkan data seperti Tabel 1.

Tabel 1. Kinerja Disk Mill

\begin{tabular}{|c|c|c|c|c|c|}
\hline $\begin{array}{c}\text { Ulangan } \\
\text { ujii coba }\end{array}$ & $\begin{array}{c}\text { Berat } \\
\text { bahan baku } \\
\text { (gram) }\end{array}$ & $\begin{array}{c}\text { Putaran } \\
\text { mesin } \\
\text { (Rpm) }\end{array}$ & $\begin{array}{c}\text { Berat } \\
\text { bahan jadi } \\
\text { (gram) }\end{array}$ & Waktu & $\begin{array}{c}\text { Rata - RataTingkat } \\
\text { kehalusan tepung } \\
\text { (vitamin unggas) } \\
\text { (mesh) }\end{array}$ \\
\hline 1 & 5200 & 2800 & 4980 & 20 & 100 \\
\hline 2 & 5200 & 2800 & 5195 & 20 & 100 \\
\hline 3 & 5200 & 2800 & 5010 & 20 & 100 \\
\hline
\end{tabular}



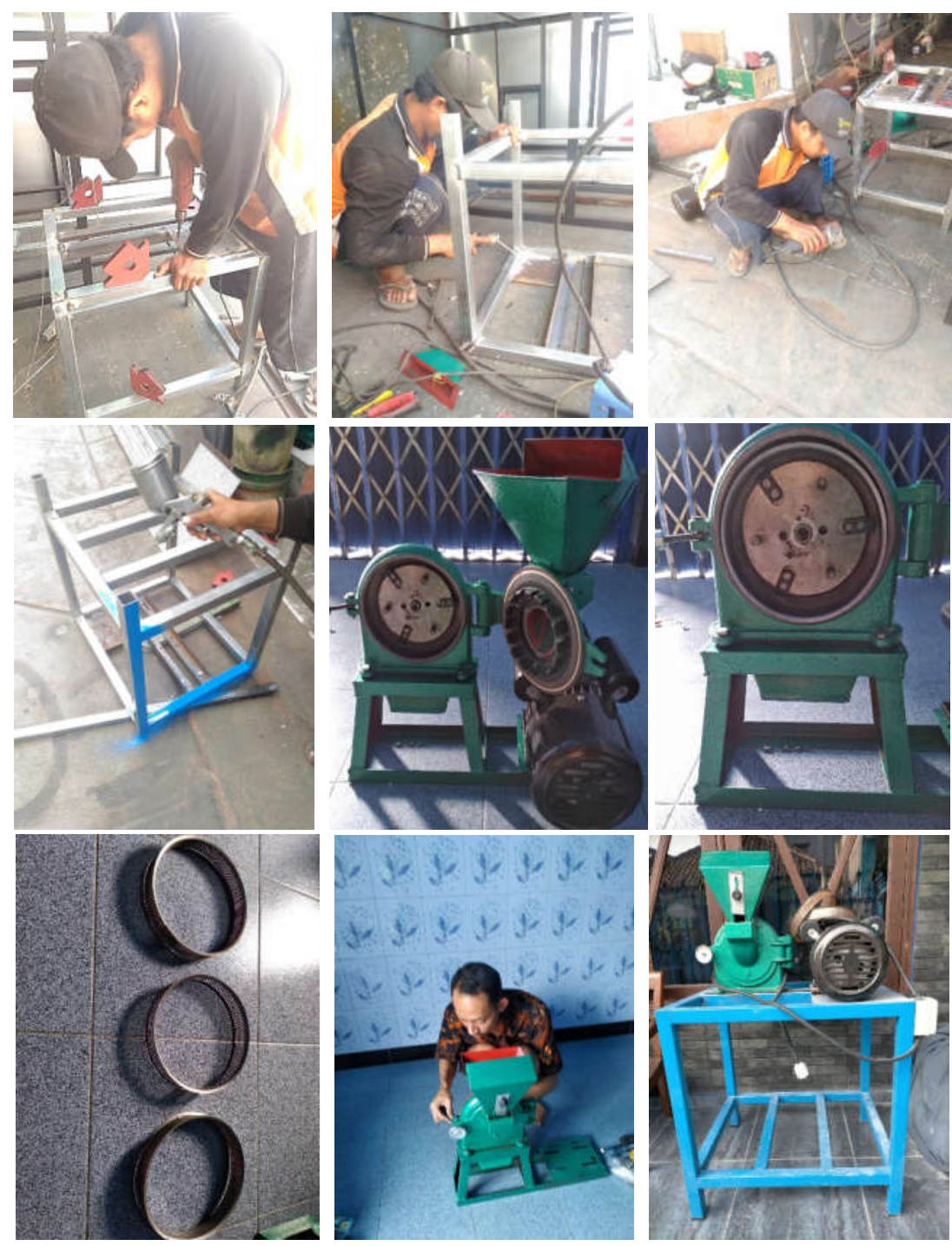

Gambar 6 Proses Pembuatan Mesin Disk Mill Vitamin Unggas

Dari hasil kegiatan uji coba dan pelatihan, untuk hasil produk dari tingkat kehalusan sudah sesuai dengan yang diharapkan. Setelah bahan baku diproses mesin disk mill dilakukan pengayakan. Hasil dari pengayakan tersebut memiliki tingkat kehalusan yang rata yaitu 100 mesh. Tetapi jika dilihat dari berat bahan baku dibandingkan dengan berat bahan jadi terjadi pengurangan kurang lebih $100-200$ gram. Sehingga perlu adanya perbaikan dengan menggunakan full cover pada mesin disk mill vitamin unggas agar bahan jadi tidak terbuang terlalu banyak.

Selain mesin disk mill vitamin unggas, pada kegiatan pengabdian masyarakat ini juga memberikan ide atau terobosan dalam proses pengemasan vitamin unggas. Dari hasil sebelumnya, model pengemasan yang dilakukan mitra menggunakan karung sehingga mudah sekali menggumpal saat dilakukan penyimpanan. Hal ini dikarenakan kelembaban udara didalam ruangan yang mempengaruhi (Sugiarti, no date). Dengan mengetahui hal tersebut sehingga diusulkan menggunakan kemasan dari bahan alumunium foil seperti yang ditunjukkan pada Gambar 8. 


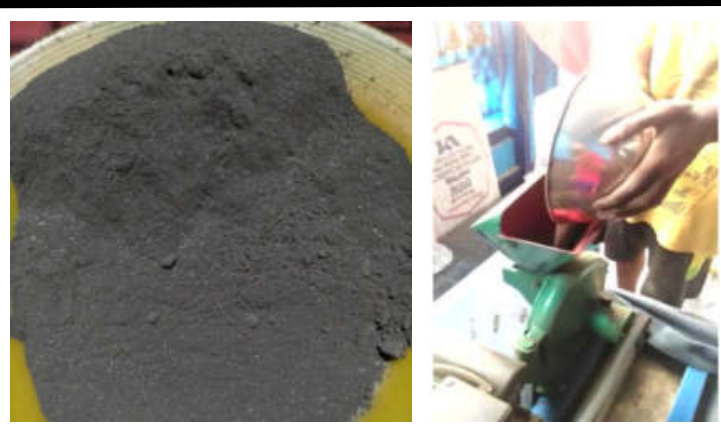

Gambar 7. Hasil Kegiatan Uji Coba dan Pelatihan

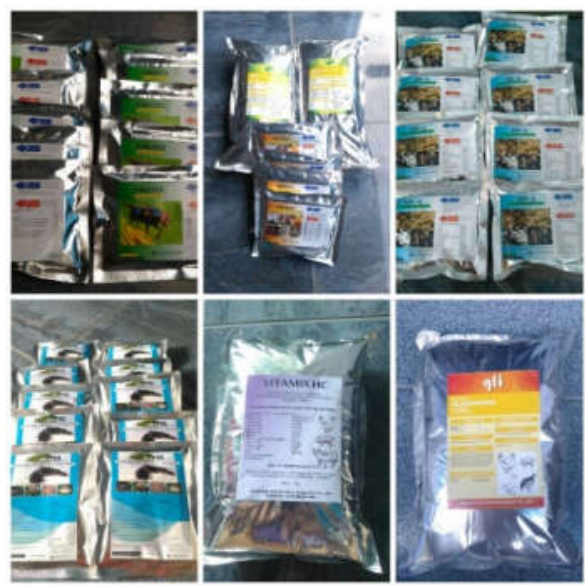

Gambar 8. Produk Menggunakan Kemasan Alumunium Foil

\section{DAMPAK DAN MANFAAT}

Dampak dan manfaat yang didapatkan mitra setelah dilakukan pengabdian masyarakat dengan menerapkan teknologi pada UMKM Anugerah yang bergerak dibidang produksi vitamin unggas adalah meningkatnya jumlah produk yang dihasilkan. Dari data sebelumnya, rata - rata untuk mengerjakan produk vitamin unggas dengan jumlah $500 \mathrm{~kg}$ membutuhkan waktu 6 jam dan jumlah pekerja 3 orang. Dengan adanya mesin disk mill vitamin unggas untuk mendapatkan produk $500 \mathrm{~kg}$ membutuhkan waktu 3 jam dengan jumlah pekerja 1 orang. Selain menghemat waktu, mitra juga dapat menghemat pengeluaran biaya produksi sehingga keuntungan yang didapatkan sekarang meningkat $25 \%$ dari keuntungan sebelumnya.

\section{KESIMPULAN}

Dari hasil kegiatan pengabdian masyarakat yang bekerja sama dengan mitra UMKM Anugerah dapat berjalan sesuai yang diharapkan. Hasil kegiatan ini didapatkan mesin disk mill vitamin unggas dan kemasan berbahan alumunium foil. Mesin disk mill vitamin unggas ini memiliki kapasitas $150 \mathrm{~kg} / \mathrm{jam}$. Jika produksi yang dihasilkan $500 \mathrm{~kg}$ membutuhkan waktu 3 jam dengan jumlah pekerja 1 orang. Sehingga mitra dapat menghemat waktu dan dapat menghemat pengeluaran biaya produksi sehingga keuntungan yang didapatkan sekarang meningkat $25 \%$ dari keuntungan sebelumnya. Sedangkan kemasan yang digunakan oleh mitra sekarang menggunakan kemasan alumunium foil sehingga tampilan produk lebih menarik dan mampu menahan produk menjadi tetap kering. 


\section{UCAPAN TERIMA KASIH}

Kami mengucapkan terima kasih banyak kepada Lembaga Penelitian dan Pengabdian Masyarakat (LPPM) Institut Teknologi Nasional Malang yang telah memberikan dana terhadap kegiatan pengabdian masyarakat ini.

\section{REFERENSI}

Aman, S. et al. (2017) 'The Exfoliation of Graphite Particles in the Vibratory Disk Mill', Chemie-Ingenieur-Technik, 89(9), pp. 1185-1191. doi: 10.1002/cite.201600124.

Baccara, M., Lee, S. and Yariv, L. (2020) 'Task Allocation and On-the-job Training', (October).

Djiwo, S., Pohan, G. A. and Praswanto, D. H. (2019) 'Dryer Segel Botol Plastik Untuk Peningkatan Kwalitas Kemasan Botol Vitamin Unggas Di Kecamatan Purwosari Kabupaten Pasuruan', Jurnal Aplikasi Dan Inovasi Ipteks 'Soliditas' (J-Solid), 1(2), p. 84. doi: $10.31328 /$ js.v1i2.901.

Kafiabad, S. T., Kazemi Zanjani, M. and Nourelfath, M. (2020) 'Integrated Planning of Operations and on Job Training in Maintenance Logistics Networks', Reliability Engineering and System Safety, 199. doi: 10.1016/j.ress.2020.106922.

Mahmud, W. (2020) 'Implementasi Forward Chaining dan Metode Simpleks untuk Menentukan Ransum Unggas yang Ekonomis', Jurnal Teknik Informatika dan Sistem Informasi, 6(1), pp. 72-81. doi: 10.28932/jutisi.v6i1.2320.

Marsigit, W. et al. (2020) 'Pengaruh Jenis Kemasan dan Lama Penyimpanan Dalam Effect of Packaging Type and Storage at Room', 92, pp. 57-67.

Nurhaeda, Muhammad Siri Dangnga, dan N. (2019) 'Faktor-Faktor yang Mempengaruhi Pendapatan Nelayan (Studi Kasus Di Kelurahan Takkalasi Kecamatan Balusu Kabupaten Barru)' Jurnal Pendidikan Teknologi Pertania, 5, pp. 61-66.

Praswanto, D. H., Djiwo, S. and Setyawan, E. Y. (2019) 'Perancangan Mesin Penggiling Bumbu Pecel Menggunakan Penggerak Motor Listrik Dengan Metode Reverse Engineering', Jurnal Aplikasi Dan Inovasi Ipteks 'Soliditas' (J-Solid), 2(1), p. 11. doi: 10.31328 js.v2i1.1283.

Sugiarti, Y. (no date) 'Bumbu Instan Pindang Tulang Iga Sapi (The Effect of Packaging and Temperature on The Storage of Beef Ribs Pindang Instant Seasoning )', pp. 86-91.

Sukmafitri, A., Ragadhita, R. and Nandiyanto, A. B. D. (2020) 'Disk Rotation Speed and Diameter of Impactor in Disk Mill on Particle Size Distribution from Rice Husk', Journal of Engineering Science and Technology, 15(3), pp. 1698-1704. 